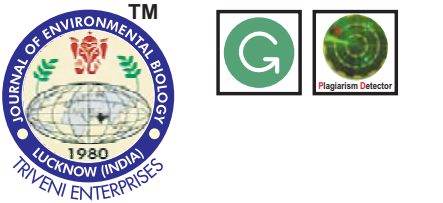

DOI : http://doi.org/10.22438/jeb/38/6/MS-183

\section{Journal of Environmental Biology}

ISSN: 0254-8704 (Print)

ISSN: 2394-0379 (Online)

CODEN: JEBIDP

\title{
Assessment of air pollution tolerance index of some selected roadside plants of Bhubaneswar city of Odisha State in India
}

\section{Authors Info}

S. Acharya, R.C. Jena, S.J. Das, C. Pradhan and P.K. Chand ${ }^{*}$

Environmental Science Laboratory, Post Graduate Department of Botany, Utkal University, Vani Vihar, Bhubaneswar - 751004 , India

${ }^{*}$ Corresponding Author Email pkchanduubot@yahoo.co.in

Key words

APTI

Sensitive plants

Tolerant plants

Vehicular pollution

Publication Info

Paper received : 16.10 .2015

Revised received : 20.07.2016

Re-revised received: 06.05.2017

Accepted : 24.04.2017

\section{Abstract}

Aim : A periodic evaluation of air pollution tolerance index (APTI) of thirteen different plant species (including nine trees and four shrubs), distributed alongside the national highway (NH-5) passing through Bhubaneswar, Odisha, India was carried out aiming at proper selection of tolerant plants to be used as biofilters against harmful vehicular air pollutants.

Methodology : Leaf samples were analysed for APTI scores which were formulated using four different parameters viz., leaf extract $\mathrm{pH}$, relative water content, total chlorophyll and ascorbic acid accumulated in leaftissues.

Results : Based on the average APTI score point computed from data obtained during winter and summer season, Cascabela thevetia was the most tolerant while Mangifera indica and Neolamarkia cadamba were moderately tolerant. Ficus benghalensis, Ricinus communis, Cassia siamea, Ficus religiosa and Bougainvillea spectabilis showed intermediate tolerance, whereas the remaining five species namely Terminalia catappa, Calotropis gigantea, Psidium guajava, Artocarpus heterophyllus and Azadirachta indica were sensitive.

Interpretation : The reported APTI tolerant plant species can be recommended for inclusion in the urban greenbelt development plan and city landscaping, while the sensitive ones can be used as indicators of vehicular air pollution.

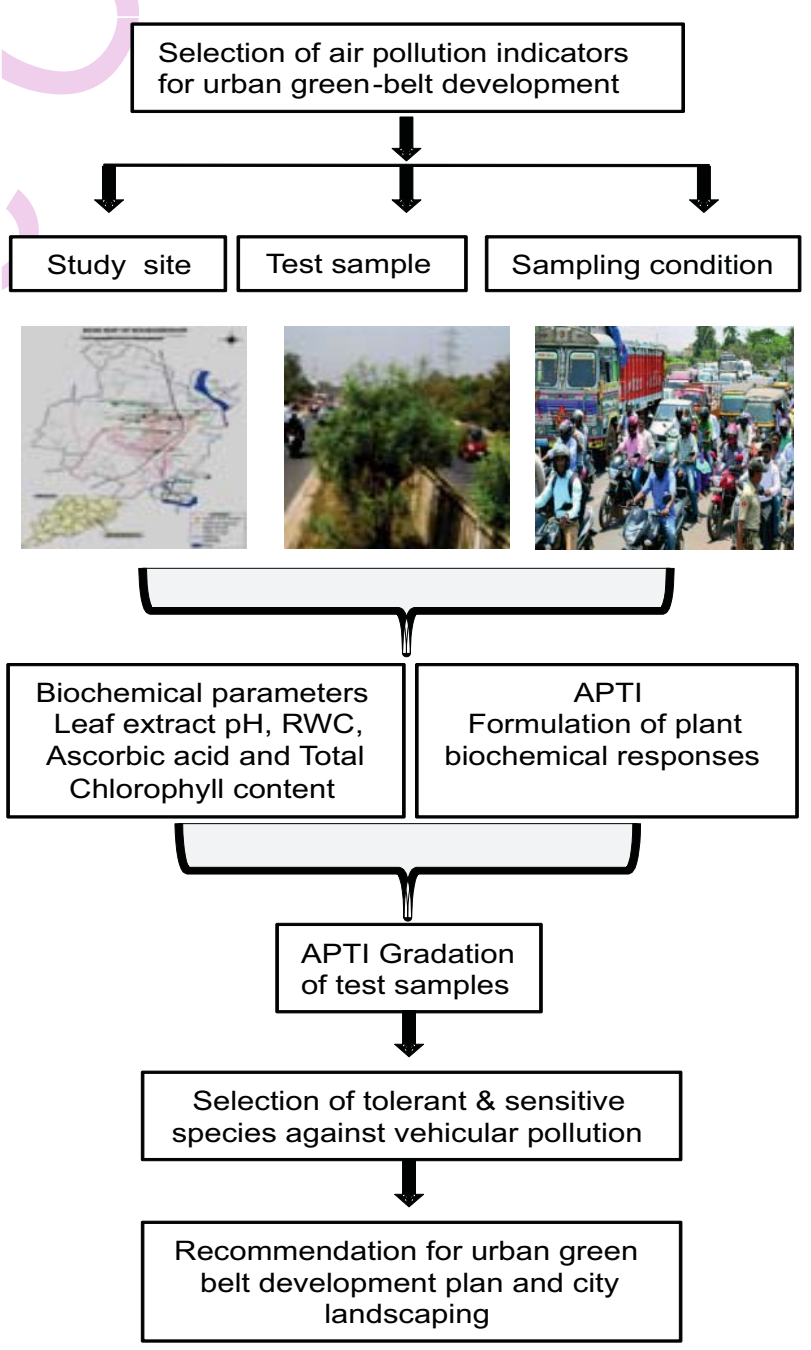




\section{Introduction}

One of the major environmental concerns in most of the cities across the globe is vehicular air pollution and the present research focus on the role of urban plantation, landscape development, greenbelt development, etc., in mitigating the adverse impacts of air pollutants. Anthropogenic activities are the driving force to alter the air quality by generating different toxic chemicals, particulate matter, biomedical waste, etc., that cause harm to humans and other living organism (Anonymous, 2008). The ambience in urban atmosphere is continuously affected by emissions from both mobile and stationary combustion sources. Mobile sources contribute to the emission of major urban air pollutants including nitrogen oxides $\left(\mathrm{NO}_{\mathrm{x}}\right)$, sulphur oxides $\left(\mathrm{SO}_{\mathrm{x}}\right)$, carbon monoxide $(\mathrm{CO})$, particulate matter $(\mathrm{PM})$, lead $(\mathrm{Pb})$, photochemical oxidants such as ozone $\left(\mathrm{O}_{3}\right)$ and ozone precursors like unburnt hydrocarbons, $\mathrm{NO}_{2}$ and volatile organic compounds (VOCs) (Costa, 2001; Cohen et al., 2004). In fact, about $60 \%$ of air pollution in most modern cities is caused by automobile exhausts only (Gaikwad et al., 2006; Wilson et al., 2007). Such air pollutants are responsible for variety of diseases in plants, animals or human beings.

Plants play a vital role in biogeochemical cycling of nutrients to maintain the ecological balance in nature. They also provide enormous leaf area for impingement and act as a sink or living filters to minimize air pollution by absorption, adsorption, detoxification, accumulation and/or various metabolic activities without sustaining serious foliar damage or decline in growth (Shannigrahi et al., 2004; Escobedo et al., 2008). Planting of trees and shrubs for abatement of air pollution is an effective approach adopted worldwide (Escobedo et al., 2008; Nugrahani et al., 2012).

Random planting of some trees or shrubs may not suffice to be effective in combating air pollution; proper selections of plant species as well as sustainable landscape management plan are necessitated. Urban planners and architects design several models for green belt development which include various factors such as distance of the green belt from pollution source, density, width and height of the plants, etc. (Chaulya et al., 2001). Nevertheless, models for a green belt development also need to consider the selection of tree and shrub species based on their relative pollution tolerance ability. APTI provides a mean for discriminating pollution-tolerant plant species from the pollutionsensitive ones. It helps generate valuable information for landscapers and greenbelt designers. While hyper-tolerant plant species are to be selected for large-scale plantation programmes as a component of social forestry in metropolitan areas, sensitive varieties may be used as bio-indicators of air pollution sensitive zones (Seyyednejad et al., 2011).

Individual biochemical and physiological parameters often demonstrate conflicting results for some species (Han et al., 1995). Conversely, the APTI scores based on the combination of four salient parameters, such as ascorbic acid content (Hoque et al., 2007), chlorophyll content (Flowers et al., 2007), leaf extract $\mathrm{pH}$ (Klump et al., 2000) and relative water content (RLW) gave more reliable results than obtained with any of the aforesaid single parameters tested individually (Singh et al., 1991; Lakshmi et al., 2008; Choudhury et al., 2009). Therefore, in the present study, a periodic evaluation of APTI was carried out using RLW, chlorophyll, leaf extract $\mathrm{pH}$ and ascorbic acid for some of the abundant trees and shrubs either growing naturally or planted adjacent to the Chennai-Kolkata national highway via Bhubaneswar (NH-5). The outcome of this investigation is expected to facilitate proper selection of species for urban plantation program.

\section{Materials and Methods}

Study site : The present research was mainly confined to the area (14 km stretching from Palasuni to Khandagiri square) adjacent to the NH-5 passing through Bhubaneswar, the capital city of the east coast of Odisha, India. The average temperature, precipitation and humidity for the month of May, 2014 in Bhubaneswar was observed to be $30-38{ }^{\circ} \mathrm{C}, 20.2-23.5 \mathrm{~mm}$ and $62-69 \%$, whereas for the month of December of the succeeding year (2015) these values were $16-28{ }^{\circ} \mathrm{C}, 4-15 \mathrm{~mm}$ and $58-66 \%$, respectively.

Samples and experimental set-up : The study was conducted during the winter and summer season, precisely in the month of December, 2014 and May, 2015 respectively. Among thirteen plant species tested, nine were trees and four were shrubs (Table 1). Sampling of plants selected at different study sites were based on a completely randomized design. Leaf samples were collected from the breast height of the plants at three different times of a day for record and analysis ( 7 a.m., 1 p.m. and 7 p.m.) from different sites along the $\mathrm{NH}-5$ and placed in the marked polythene zip pack bags. These bags were placed in liquid nitrogen container for further use. In laboratory, samples were stored at $-20^{\circ} \mathrm{C}$ till use.

Relative leaf water content : The percentage of relative leaf water content was determined by using fresh weight, dry weight and turgid weight of leaf samples following the method described by Singh (1977). Fresh leaves were weighed using an electronic digital balance, thereafter immersed in double distilled water for $5 \mathrm{hrs}$ followed by overnight storage at $4{ }^{\circ} \mathrm{C}$, blot dried and then weighed to obtain the turgid weight. The dry weight was determined after the leaves were dried overnight in an oven at $70^{\circ} \mathrm{C}$.

Total chlorophyll content : Freshly collected mature leaf samples $(500 \mathrm{mg}$ ) were ground in $5 \mathrm{ml}$ methanol using a homogenizer and kept overnight at room temperature $\left(27 \pm 2^{\circ} \mathrm{C}\right)$. The homogenate was centrifuged at $4000 \mathrm{rpm}$ for $10 \mathrm{~min}$. The supernatant was collected in a container and absorbance was recorded at $665.2 \mathrm{~nm}$ and $652.0 \mathrm{~nm}$ with UV-Visible Spectrophotometer (Lambda 25, Perkin Elmer, U.S.A.). Calculations were made to determine the chlorophyll content ( $\mathrm{mg}$ $\mathrm{g}^{-1}$ f.wt.) by the standard formula (Porra, 2002). 
Leaf extract $\mathrm{pH}$ : Half a gram of fresh leaf sample was homogenized in $50 \mathrm{ml}$ of deionized water. The homogenate was centrifuged at $4000 \mathrm{rpm}$ in room temperature and $\mathrm{pH}$ of the supernatant was measured by a digital pH meter (Systronics Ltd., India).

Ascorbic acid content analysis : Freshly collected leaves (100 $\mathrm{mg}$ ) were homogenized with $6 \%$ meta-phosphoric acid and centrifuged at $14,000 \times \mathrm{gg}$ for $10 \mathrm{~min}$. Two milliliters of $2 \%$ sodium molybdate and $2 \mathrm{ml}$ of $0.15 \mathrm{~N}$ sulphuric acid were mixed, chilled and then $1 \mathrm{ml}$ of monobasic sodium phosphate was added. These were mixed with $1 \mathrm{ml}$ of supernatant, incubated for $40 \mathrm{~min}$ in a boiling water bath at $60{ }^{\circ} \mathrm{C}$, then cooled and centrifuged at 4000 $\times \mathrm{g}$ for $10 \mathrm{~min}$. Absorbance was taken at $660 \mathrm{~nm}$ with 3 replicates The ascorbic acid content in leaves were expressed in $\mathrm{mg} \mathrm{g}^{-1} \mathrm{f}$.wt. from the regression equation obtained from the standard slope with L-ascorbic acid (Mitsui and Ohta, 1961).

APTI: APTI of each plant species was calculated by incorporating the values of relative water content, leaf extract $\mathrm{pH}$, total chlorophyll and ascorbic acid content according to Bakiyaraj and Ayyappan (2014).

Statistical analysis : All the results were expressed as mean \pm $\mathrm{SD}$. The results were analyzed for statistical significance by Duncan's Multiple Range Test at $95 \%$ level of confidence. The regression analysis was done between different biochemical parameters and APTI values to depict their correlations following standard statistical procedure.

\section{Results and Discussion}

Variations among thirteen selected plant species was evident with respect to leaf extract $\mathrm{pH}$ values recorded at three experimental time points during winter and summer season. The highest leaf extract $\mathrm{pH}$ value during winter (6.74) was recorded in banyan ( $F$. benghalensis) and peepal tree ( $F$. religiosa) during mid day (at 1 p.m.), followed by shrub Yellow oleander (C. thevetia; 6.57 ) at the same time (Table 1). On the other hand, during summer mid day, $C$. thevetia had the maximum leaf extract $\mathrm{pH}$ (6.67) followed by $F$. religiosa (6.65) as illustrated in Table 2. Interestingly, Siamese cassia (C. siamea) plants exhibited the lowest $\mathrm{pH}$ at all three time points regardless of season. For a majority of test plant species, leaf extract $\mathrm{pH}$ values were minimum at early morning time and maximum at mid day irrespective of season. Higher $\mathrm{pH}$ value of leaf extracts is known to influence stomatal permeability to air pollutants which alters leaf gas exchange capacity as well as transpiration rate (Swami et al., 2004).

Total chlorophyll content also varied with plant species tested as well as demonstrating season-specificity. During winter Great bougainvillea (B. spectabilis) had maximum total chlorophyll (1.92 $\mathrm{mg} \mathrm{g}^{-1}$ f.wt.) at morning (7 a.m.) which was reduced to $1.72 \mathrm{mg} \mathrm{g}^{-1} \mathrm{f}$.wt. and further to $1.23 \mathrm{mg} \mathrm{g}^{-1} \mathrm{f}$.wt. at mid day (1 p.m.) and evening time (7 p.m.) (Table 1). Similarly, the Total chlorophyll content in neem/margosa tree (A. indica) showed a declining trend with the progression of day i.e., $1.79 \mathrm{mg}$ $\mathrm{g}^{-1}$ f.wt., $1.54 \mathrm{mg} \mathrm{g}^{-1}$ f.wt. and $1.32 \mathrm{mg} \mathrm{g}^{-1}$ f.wt. at 7 a.m., 1 p.m. and 7 p.m. respectively. An exception from general trend was observed with castor bean (R. communis). On the other hand, during summer season jackfruit tree ( $A$. heterophyllus) had highest total chlorophyll content (2.36 $\mathrm{mg} \mathrm{g}^{-1}$ f.wt.) recorded at 7 a.m. followed by reduction in values to $1.53 \mathrm{mg} \mathrm{g}^{-1}$ f.wt. by evening $(7 \mathrm{p} . \mathrm{m}$.) as illustrated in Table 2. A similar trend was observed in mango tree (M. indica) i.e., $1.58 \mathrm{mg} \mathrm{g}^{-1}$ f.wt. (7 a.m.), $1.10 \mathrm{mg} \mathrm{g}^{-1}$ f.wt. (1 p.m.) and $0.79 \mathrm{mg} \mathrm{g}^{-1}$ f.wt. (7 p.m.). However, a reverse trend was noticed in castor bean.

Chlorophyll content is an important biochemical parameter indicating its sensitivity towards air pollutants as it plays a vital role in photosynthetic carbon dioxide fixation as well as growth and development of biomass (Ninave et al., 2001; Liu et al., 2012). In the present context, higher pollution level in the form of vehicular exhausts lowered the chlorophyll content. Mir et al. (2008) observed that increasing levels of automobile pollution decreased total chlorophyll content in higher plants. Changes in accumulation of certain biochemical compounds in plants were observed due to the effect of certain air pollutants (Tripathi et al., 2007; 2009). Jyothi and Jaya (2010) reported chloroplasts as the primary site of attack in the leaves of plants exposed to air pollution, thereby reducing photosynthetic yield. The lower and higher chlorophyll contents in different times in a day may be attributed to time dependent change in traffic rush. The former may be due to more pollution stress by hindering chlorophyll biosynthesis or various chlorophyll degradation products (fluorescent/non-fluorescent chlorophyll catabolite) or stress induced chlorosis, pheophytinisation, reverse bleaching, etc. (Thawale et al., 2011). Conversely, higher chlorophyll content was observed mostly during morning hours which might be due to plants' innate tolerance mechanism against air pollutant-induced oxidative stress.

Ascorbic acid is a non-enzymatic antioxidant known to confer protection in plants against adverse effects of oxidative stress. Plants selected for the present investigation differed in their ascorbic acid content which varied during morning to evening time of the day influenced in a season-specific manner. During winter, the shrubby species, yellow oleander (C. thevetia) exhibited maximum ascorbic acid content (94.31 $\mathrm{mg} \mathrm{g}^{-1} \mathrm{f}$.wt.) in the evening time showing a several fold enhancement over that recorded during early morning (6.88 $\mathrm{mg} \mathrm{g}^{-1} \mathrm{f}$.wt.). A comparable tendency was noticed with the mango tree (M. indica) i.e., 4.02 $\mathrm{mg} \mathrm{g}^{-1}$ f.wt. at 7 a.m. and $89.85 \mathrm{mg} \mathrm{g}^{-1}$ f.wt.) at 7 p.m. (Table 1). During summer season, the ascorbic acid content in C. siamea decreased from $10.84 \mathrm{mg} \mathrm{g}^{-1}$ f.wt. (7 a.m.) to $5.13 \mathrm{mg} \mathrm{g}^{-1}$ f.wt. at mid day (1 p.m.) and thereafter, boosted to as high as $159.78 \mathrm{mg}$ $\mathrm{g}^{-1}$ f.wt. by evening time (7 p.m.). C. thevetia as well as a tree species (M. indica) also displayed a similar trend. Ascorbic acid quantity in C. thevetia varied from $5.92 \mathrm{mg} \mathrm{g}^{-1}$ f.wt. (7 a.m.) to 2.99 $\mathrm{mg} \mathrm{g}^{-1}$ f.wt. (1 p.m.) and $96.33 \mathrm{mg} \mathrm{g}^{-1}$ f.wt. (7 p.m.). For mango tree, the ascorbic acid content were $4.10 \mathrm{mg} \mathrm{g}^{-1} \mathrm{f}$.wt., $3.18 \mathrm{mg} \mathrm{g}^{-1} \mathrm{f}$.wt. and $98.86 \mathrm{mg} \mathrm{g}^{-1}$ f.wt. at 7 a.m., 1 p.m. and 7 p.m., respectively 


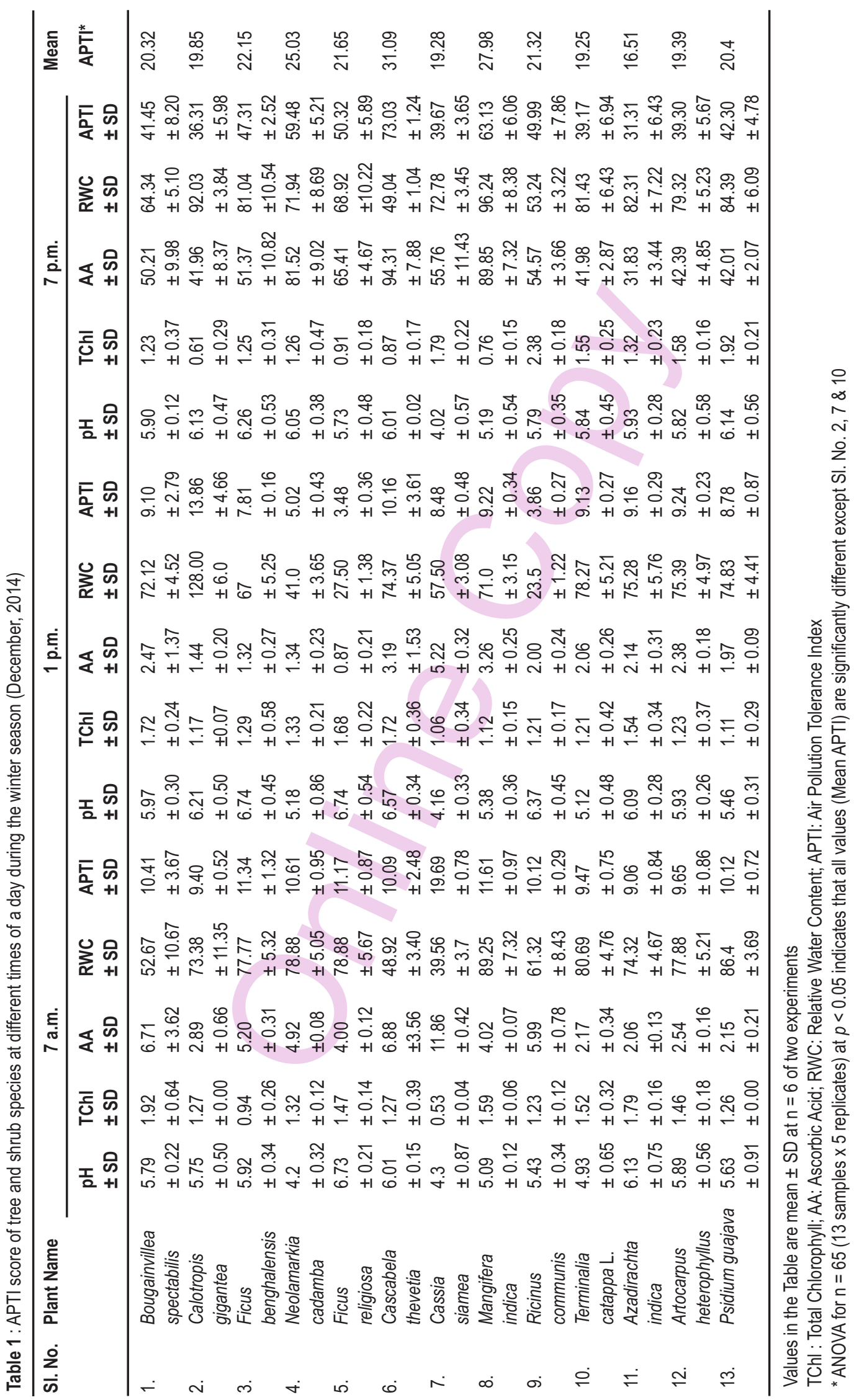




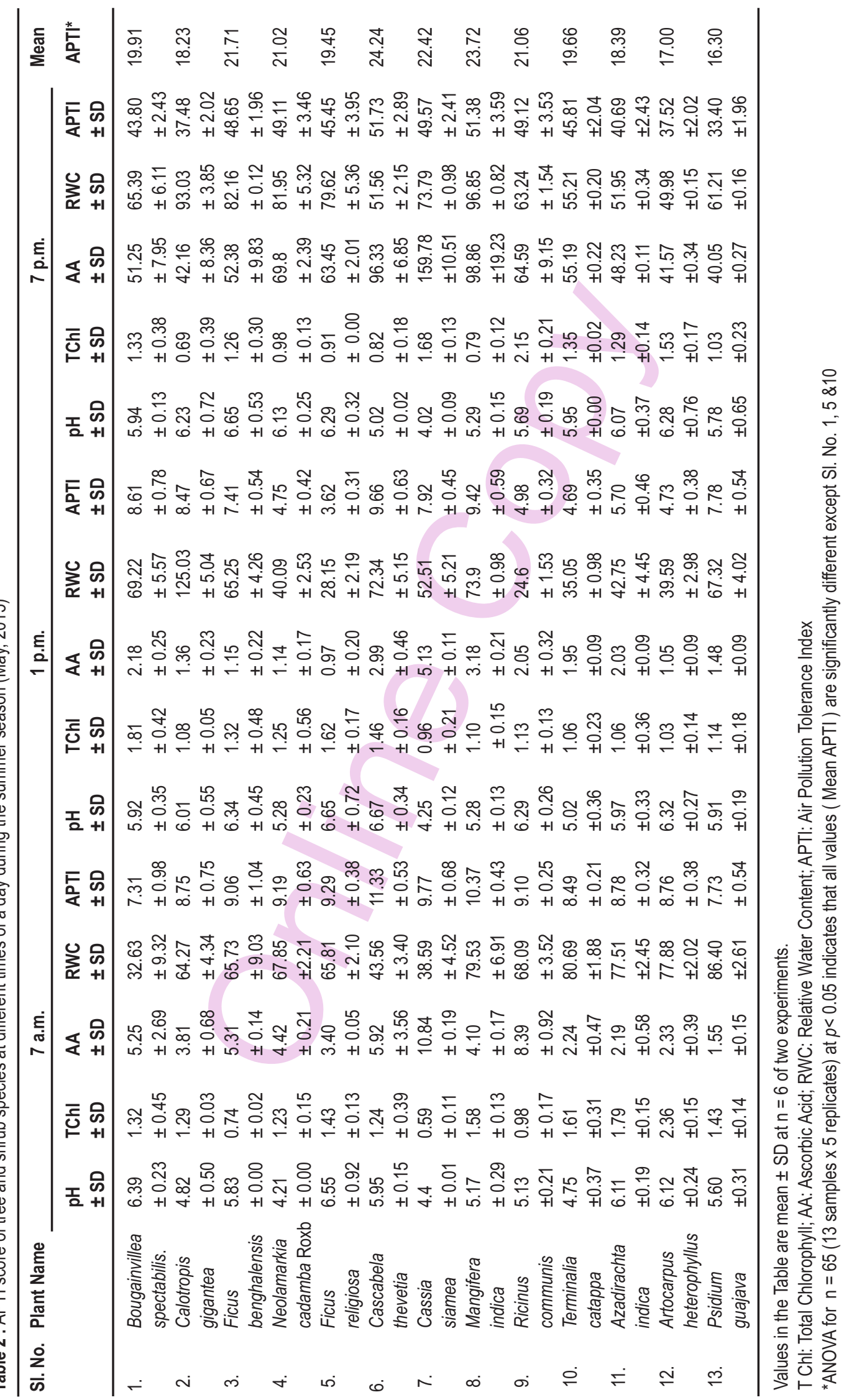


(Table 2). The overall trend of reduction in the ascorbic acid content regardless of plant species examined observed at noon can perhaps be explained on the basis of low vehicular traffic, particularly during hot summer mid day time. The highest ascorbic acid concentration was noticed during evening hours when vehicular pollution was most intense, the latter producing reactive oxygen species viz. superoxides, hydroxyl free radicals etc. during photo-oxidation of $\mathrm{SO}_{2}$ to $\mathrm{SO}_{3}$ in leaf tissues, might be due to free radical scavenging activity of ascorbic acid molecule. High ascorbic acid concentration of plant species is a sign of its antioxidative tolerance against sulphur dioxide pollution (Yunus etal., 1996).

Differential relative leaf water content (RWC) was observed in selected plants at varying daily check-time points with a seasonal effect being explicit. For instance, during winter, in peepal plant ( $F$. religiosa) highest RWC was recorded at 7 O'clock in the morning $(78.88 \%$ ) which declined up to $27.50 \%$ by noon time and thereafter, rose up to $68.92 \%$ by 7 O'clock in the evening (Table 1). A similar tendency was noted in guava plants (P. guajava) in which RWC values were $86.4 \%, 74.83 \%$ and $84.39 \%$ at morning, mid day and evening respectively. Contrarily, during summer season, RWC values in guava plants demonstrated a continuously falling trend i.e., $86.4 \%$ (7 a.m.), $67.32 \%$ (1 p.m.) and $61.21 \%$ (7 p.m.) as depicted in Table 2. Perhaps, the recovery mechanism of restoring RWC content during winter days has failed to occur with equal effectiveness during hot summer days. RWC of a leaf is the water present in it relative to its full turgidity. Relative water content is associated with protoplasmic permeability in cells. It causes loss of water and dissolved nutrients which may result in early senescence of leaves (Agrawal et al., 1997). Therefore, it is believed that plants with high relative water content may be tolerant to high density of gaseous pollutants released from auto exhausts during traffic peak hours.

The gradation of tolerance (tolerant, moderately tolerant, intermediate tolerant and sensitive) among thirteen different plant species was calculated, based on the average APTI score point recorded, during winter and summer season (Table 1 and 2). C. thevetia was found to be the most tolerant holding the highest average APTI score point (27.67). Findings of Mahecha et al. (2013) are in consistence with the present investigation that Santalum album shows the highest APTI value. Two other plants, namely M. indica, and N. cadamba, with closer APTI score points as 25.85 and 23.03 were moderately tolerant. As many as five different plant species showed intermediate tolerance viz. F. benghalensis (21.93), R. communis (21.20), C. siamea (20.85), F. religiosa (20.55) and B. spectabilis (20.11); whereas the remaining five species namely $T$. catappa (19.46), Calotropis gigantea (19.04), P. guajava (18.35), A. heterophyllus (18.19) and $A$. indica (17.45) were found to be sensitive based on APTI gradation. Similar results were obtained for Eucalyptus $\mathrm{sp}$ (6.52), which exhibited higher APTI values reflecting a higher tolerance level, and Murraya koenigii (0.81) which showed lower APTI values indicating sensitivity to air pollution (Bakiyaraj and
Ayyappan, 2014). The $\mathrm{pH}$ (slope $=-0.01, r^{2}=0.29$ ), total chlorophyll (slope $=-0.01, r^{2}=0.69$ ) and relative leaf water content (slope $=-0.14, r^{2}=0.12$ ) showed negative correlation, whereas ascorbic acid (slope $=1.50, r^{2}=0.98$ ) showed a positive correlation with APTI for the tolerant plant species (data not shown). Such an inference is based on data recorded during evening hours when traffic induced pollution stress was intense (Govindaraju et al., 2011). In the present investigation, shrubby species showed relatively more tolerance to air pollution than trees. It is believed that tolerant plants may act as hyperaccumulators of air pollutants (Prasanna et al., 2005).

The present study is a rewarding attempt aimed at determining the extent of air pollution tolerance or sensitivity employing APTI score points to distinguish different plant species. Four species namely C. thevetia, M. indica, C. siamea and $N$. cadamba which have been identified as tolerant against air pollution may be suggested for plantation along the busiest highways of tropical and subtropical regions. On the contrary, A. indica, A. heterophyllus, P. guajava and Calotropis gigantea being relatively sensitive species may be used as biosensor or indicator plants in context of vehicular air pollution. Lohe et el. (2015) observed that Eucalyptus globus had the highest degree of tolerance at all sites of intense traffic in Dehradun, India followed by Ficus religiosa > Mangifera indica > Polyalthia longifolia > Phyllanthus emblica > Citrus limon > Lantana camara. According to Muhammad et. al. (2016) Ficus religiosa was the most tolerant with highest APTI value (9.09), while Callistemon citrinus showing the lowest APTI value (7.86) indicated its sensitivity to air pollution. In essence, APTI scorecard system provides a rapid, cost effective and reliable scientific formulation thereby offering a smart strategy in selecting air pollution tolerant plant species suitable for plantation programmes in pollution-prone areas.

\section{Acknowledgment}

The authors gratefully acknowledge the Head of PostGraduate Department of Botany, Utkal University, Bhubaneswar, Odisha, India for providing necessary laboratory facility for the work.

\section{References}

Agrawal, S. and S.L.Tiwari: Susceptibility level of few plants on the basis of Air Pollution Tolerance Index. Indian Forest.,1, 319-322 (1997).

Anonymous : Air Pollution:http//en.wikipedia.org/wiki/Air-pollution, Retrieved (2008).

Bakiyaraj, R. and D. Ayyappan : Air pollution tolerance index of some terrestrial plants around an industrial area. Intl. J. Mod. Res. Rev., 2, 1-7 (2014).

Chaulya, S.K., M.K. Chakraborty and R.S. Singh: Air pollution modeling for a proposed limestone quarry. Water Air Soil Pollut.,126, 171191 (2001).

Choudhury, P. and D. Banerjee: Biomonitoring of air quality in the industrial town of asansol using the air pollution tolerance index approach. Res. J. Chem. Environ.,13, 46-51 (2009). 
Cohen, A.J., H.A. Ross, O. Bart, K.D. Pandey, M. Krzyzanowski, N. Künzli, K. Gutschmidt, Arden, Pope III C, R. Isabelle, J.M. Samet and K.R. Smith: Urban air pollution. In: Comparative Quantification of Health Risks (Eds.: M. Ezzati, A.D. Lopez, A. Rodger and C.J.L. Murray). Geneva: World Health Organization., 2, 1353-1434 (2004).

Costa, D.L.: Air pollution. In: Casarett and Doull's Toxicology: the Basic Science of Poisons (Ed.: C.D. Klaassen). NY USA: McGraw-Hill., 979-1012 (2001).

Escobedo, F.J., J.E. Wagner, D.J. Nowak, D.L. Maza, M. Rodriguez and D.E. Crane: Analyzing the cost effectiveness of Santiago, Chile's policy of using urban forest to improve air quality. J. Environ. Manage., 86,148-157 (2008).

Flowers, M.D., E.L. Fiscus and K.O. Burkey: Photosynthesis, chlorophyll fluorescence and yield of snap bean (Phaseolus vulgaris L.) genotype differing in sensitivity to ozone. Environ. Exp. Bot., 61, 190-198 (2007).

Gaikwad, U.S., C.D. Ranade and J.M. Gadgi: Plants as bio indicators of automobile exhaust pollution - a case study of Sangli City. J Inst. Engg. (India). Environ. Engg. Divn., 86, 26-28 (2006).

Govindaraju, M., R.S. Ganeshkumar, V.R. Muthukumaran and P.Visvanathan: Identification and evaluation of air pollution tolerant plants around lignite based thermal power station for greenbelt development. Environ. Sci. Pollut. Res.,19, 1210 -1223 (2011).

Han, Y., Q.Y. Wang and G.X. Han: The analysis about SOD activities in leaves of plants and resistance classification of them. $J$. Liaon.Univ., 22, 71-71 (1995).

Hoque, M.A., M.N.A. Banu and E. Okuma: Exogenous proline and glycine betaine increase $\mathrm{NaCl}$-induced ascorbate-glutathione cycle enzymes activities and proline improves salt tolerance more than glycine betaine in tobacco bright yellow -2 suspension cultured cells. J. Plant Physiol., 164, 1457-1468 (2007).

Jyothi, J.S. and D.S. Jaya: Evaluation of air pollution tolerance index of selected plant species along roadsides in Thiruvananthapuram, Kerala. J. Environ. Biol., 31, 379-386 (2010).

Klumpp, G., C.M. Furlan, M. Domingos and A. Klumpp: Response of stress indicators and growth parameters of Tibouchina pulchra Cogn. exposed to air and soil pollution near the industrial complex of Cubatao, Brazil. Sci. Total Environ., 246, 79-91 (2000).

Lakshmi, P.S., K.L. Sravanti and N. Srinivas : Air pollution tolerance index of various plant species growing in industrial areas. The Ecoscan, 2, 203-206 (2008).

Liu, Z.A., J.P. Yang and Z.C. Yang : Using a chlorophyll meter to estimate tea leaf chlorophyll and nitrogen contents. J. Plant Nutri. Soil Sci., 12, 339-348 (2012).

Lohe, R.N., B. Tyagi, V. Singh, P. Kumar, Tyagi, D.R. Khanna and R. Bhutiani : A comparative study for air pollution tolerance index of some terrestrial plant species. Global J. Environ. Sci. Manage., 1, 315-324, (2015).

Mahecha, G.S., B.R. Bamniya, N. Nair and D. Saini : Air Pollution Tolerance Index of certain plant species-a study of Madri industrial area, Udaipur (Raj.), India. Intl. J. Innov. Res. Sci. Engg. Technol., 2, 7927-7929 (2013).
Mir, Q.A., T. Yazdani, A. Kumar, K. Narain and M.Yunus: Vehicular population and pigment content of certain avenue trees. Pollut. Res., 27, 59-63 (2008).

Mitsui, A. and T. Ohta: Photooxidative consumption and photoreductive formation of Ascorbic acid in green leaves. Plant Cell Physiol., 2, 31-44 (1961).

Muhammad, S., F. Shakeel, Z. Khan, M. Hasnain, and T.A.. Cheema : Assessment of air pollution sensitivity of some selected tree species of busiest roads of Lahore city. J. Biol. \& Environ. Sci., 9, 99-105(2016).

Ninave, S.Y., P.R. Chaudhri, D.G. Gajghate and J.L. Tarar: Foliar biochemical features of plants as indicators of air pollution. Bullet. Environ.Cont. Toxicol., 67, 133-140 (2001).

Nugrahani, P., E.T. Prasetyawati, Sugijanto and H. Purnobasuki: Ornamental shrubs as plant palettes elements and bio indicators based on air pollution tolerance index in Surabaya City, Indonesia. Asian J. Biol.Sci., 3, 298-302 (2012).

Porra, R.J. : The chequered history of the development and use of simultaneous equations for the accurate determination of chlorophylls a and b. Photosyn. Res., 73, 149-156 (2002).

Prasanna, R.T., U.K. Deshpande and U.Gawaid : Effect of sulphur dioxide on protein and carbohydrate contents of some macrophytes. Pollut. Res., 24, 427-430 (2005).

Seyyednejad, S.M., K. Majdian, H. Koochak and M. Nikneland: Air Pollution Tolerance Indices of some plants around Industrial Zone in South of Iran. Asian J. Biol. Sci., 4, 300-305 (2011).

Shannigrahi, A.S., T. Fukushuma and R.C. Sharma : An overview : Anticipated air pollution tolerance of some plant species considered for greenbelt development in and around an industrial/urban area in India. Intl. J. Environ. Stud., 61, 125-137 (2004).

Sharma, S.C. and R.K. Roy: Green belt-an effective means of mitigating industrial pollution. Indian J. Environ. Prot., 17, 724-727 (1997).

Singh, S.K., D.N. Rao, M. Agrawal, J. Pandey and D. Narayan: Air pollution tolerance index of plants. J. Environ. Manage., 32, 45-55 (1991).

Swami, A.,D. Bhatt and P.C. Joshi: Effects of automobile pollution on sal (Shorea robusta) and rohini (Mallotus phillipinensis) at Asarori, Dehradun. Himalayan J. Environ. Zoo.,18, 57-61 (2004).

Thawale, P.R., S. Satheesh Babu, R.R. Wakode, S.K. Singh, S. Kumar and A.A. Juwarkar: Biochemical changes in plant leaves as a biomarker of pollution due to anthropogenic activity. Environ. Monit.Assess.,177, 527-535 (2011).

Tripathi, A.K. and M. Gautam: Biochemical parameter of plants as indicator of air pollution. J. Environ. Biol., 28, 127-132 (2007).

Tripathi, A. K., P. Tiwari, B. Mahima and D. Singh. Assessment of Air Pollution Tolerance Index of some trees in Moradabad city, India. J. Environ. Biol. 30, 545-550 (2009).

Wilson, E.J., R. Wilson and K.J. Krizek: The implications of school choice on travel behavior and environmental emissions. Transport. Res. Part D: Transport Environ., 12, 506-518 (2007).

Yunus, M. and M. Iqbal: Plant Response to Air Pollution. Chichester, Wiley (1996). 